\title{
Increased shear in the North Atlantic upper-level jet stream over the past four decades
}

Article

Accepted Version

Lee, S. H., Williams, P. D. and Frame, T. H. A. (2019) Increased shear in the North Atlantic upper-level jet stream over the past four decades. Nature, 572. pp. 639-642. ISSN 0028-0836 doi: https://doi.org/10.1038/s41586-019-1465-z Available at https://centaur.reading.ac.uk/85485/

It is advisable to refer to the publisher's version if you intend to cite from the work. See Guidance on citing.

To link to this article DOI: http://dx.doi.org/10.1038/s41586-019-1465-z

Publisher: Nature Publishing Group

All outputs in CentAUR are protected by Intellectual Property Rights law, including copyright law. Copyright and IPR is retained by the creators or other copyright holders. Terms and conditions for use of this material are defined in the End User Agreement.

www.reading.ac.uk/centaur 
Central Archive at the University of Reading

Reading's research outputs online 
Increased shear in the North Atlantic upper-level jet stream over the past four decades

\author{
Simon H. Lee, Paul D. Williams, and Thomas H. A. Frame
}

Department of Meteorology, University of Reading, Reading, U.K.

Earth's equator-to-pole temperature gradient drives westerly mid-latitude jet streams through thermal wind balance ${ }^{1}$. In the upper atmosphere, anthropogenic climate change is strengthening this meridional temperature gradient by cooling the polar lower stratosphere $^{2,3}$ and warming the tropical upper troposphere ${ }^{4-6}$, acting to strengthen the upper-level jet stream ${ }^{7}$. In contrast, in the lower atmosphere, Arctic amplification of global warming is weakening the meridional temperature gradient ${ }^{8-10}$, acting to weaken the upper-level jet stream. Therefore, trends in the speed of the upper-level jet stream ${ }^{11-}$ ${ }^{13}$ represent a closely balanced tug-of-war between two competing effects at different altitudes $^{14}$. It is possible to isolate one of the competing effects by analysing the vertical shear instead of the speed, but this approach has not previously been taken. Here we show that, while the zonal wind speed in the North Atlantic polar jet stream at $250 \mathrm{hPa}$ has not significantly changed since the start of the observational satellite era in 1979, the vertical shear has increased by $15 \%$ (with a range of $11-17 \%$ ) according to three different reanalysis datasets ${ }^{15-17}$. We further show that this trend is attributable to the thermal wind response to the enhanced upper-level meridional temperature gradient. Our results indicate that climate change is having a larger impact on the North Atlantic jet stream than previously thought. The increased vertical shear is consistent with the intensification of shear-driven clear-air turbulence expected from climate change ${ }^{18-20}$, which will affect aviation in the busy transatlantic flight corridor. We conclude that the impacts of climate change and variability on the upper-level jet stream are being partly obscured by the traditional focus on speed rather than shear. 
26 In the northern and southern hemispheres, the mid-latitude baroclinic zone of the atmosphere

27 is associated with a planetary-scale meridional temperature gradient between the equator and

28 the pole. This temperature gradient generates westerly winds that strengthen with height -

29 vertical wind shear - as a consequence of thermal wind balance ${ }^{1}$. Using pressure as a vertical

30 coordinate, the vertical shear in the zonal wind, $-\partial u / \partial p$, is related to the meridional

31 temperature gradient, $\partial T / \partial y$, by the thermal wind balance equation:

$$
-\frac{\partial u}{\partial p}=-\frac{R}{f p} \frac{\partial T}{\partial y}
$$

32 where $R$ is the specific gas constant for dry air, $f$ is the Coriolis parameter, $p$ is pressure, and

$33 y$ is northward distance. Aloft, the strong westerly winds generated by thermal wind balance

34 form the polar (or mid-latitude) jet stream, the speed of which is typically maximised near the

35 tropopause, where the sign of the meridional temperature gradient (and thus the sign of the

36 vertical shear) reverses. The polar jet stream is often described as eddy-driven, because

37 eddies are required to support non-zero surface westerlies. It is distinct from the subtropical

38 jet stream, which is primarily caused by poleward transport of angular momentum in the

39 Hadley cell ${ }^{21}$. The polar jet stream influences mid-latitude weather systems, with the storm

40 tracks being essentially a surface expression of the jet stream ${ }^{22}$. It also plays an important role

41 in commercial aircraft operations, partly because it creates strong headwinds and tailwinds on

42 busy mid-latitude flight routes ${ }^{23}$, but also because clear-air turbulence is generated by the

43 associated intense vertical wind shear.

44 The mid-latitude meridional temperature gradients are being modified by anthropogenic

45 climate change ${ }^{24}$, and the jet streams are expected to adjust in response ${ }^{23-25}$. In the lower

46 troposphere of the northern hemisphere, Arctic amplification caused primarily by lapse-rate

47 feedbacks ${ }^{26}$ is weakening the meridional temperature gradient and polar jet stream ${ }^{8-10}$. In

48 contrast, in the upper troposphere and lower stratosphere, the meridional temperature gradient 
49 is strengthening because of the combined effects of polar lower-stratospheric cooling and tropical upper-tropospheric warming, the latter caused by water vapour feedbacks releasing

51 additional latent heat and reducing the lapse rate ${ }^{7}$. The vertically integrated thermal wind 52 response is a tug-of-war between these two competing effects, with Arctic amplification 53 acting to decrease the wind speed in the upper troposphere and lower stratosphere, but polar 54 lower-stratospheric cooling and tropical upper-tropospheric warming acting to increase it. 55 These competing influences suggest that upper-level trends in the jet stream may be better discerned through changes in vertical wind shear rather than absolute wind speed.

57 Here we analyse historic trends in the upper-level vertical wind shear over the North Atlantic. 58 In future climate projections, the prevalence of clear-air turbulence at typical aircraft cruising 59 altitudes increases more here than anywhere else globally ${ }^{20}$. We use data from the ERA60 Interim reanalysis at $0.75^{\circ}$ horizontal resolution ${ }^{16}$, the NCEP/NCAR reanalysis at $2.5^{\circ}$ 61 horizontal resolution ${ }^{15}$, and the JRA-55 reanalysis at $1.25^{\circ}$ horizontal resolution ${ }^{17}$. The use of 62 three independently produced reanalysis datasets allows us to quantify the sensitivity of our 63 results to uncertainties in the state of the atmosphere. We take six-hourly data from the years 64 1979-2017 inclusive. We restrict the temporal coverage to the satellite era, because the 65 sparsity of upper-level wind observations over the North Atlantic before 1979 substantially 66 increases uncertainty in reanalysis datasets ${ }^{27}$. We consider data within the region defined by $6730-70^{\circ} \mathrm{N}$ and $10-80^{\circ} \mathrm{W}$. This latitudinal range is chosen to include the polar jet stream (and the busy transatlantic flight corridor) whilst excluding the subtropical jet stream. We focus on the shear at a pressure altitude of $250 \mathrm{hPa}$, corresponding to the climatological core of the 70 polar jet stream, and equating to a typical aircraft cruising altitude of around 34,000 feet.

71 We begin by analysing annual-mean upper-level temperature trends. As shown in Figure 1, 72 all three reanalysis datasets indicate a strengthening of the mid-latitude meridional 73 temperature gradient at $250 \mathrm{hPa}$. The $250 \mathrm{hPa}$ pressure surface evidently intersects the 
74 tropopause at around $50-60^{\circ} \mathrm{N}$, with lower-stratospheric cooling on the poleward side and 75 upper-tropospheric warming on the equatorward side. The upper-tropospheric warming trend 76 is slightly stronger in ERA-Interim and JRA-55, and the lower-stratospheric cooling trend is 77 slightly stronger in NCEP/NCAR. Despite these minor differences, the spatial patterns and 78 magnitudes of the temperature trends are broadly consistent across the datasets. Unlike the 79 warming trends, the cooling trends are generally not statistically significant (except near 80 Iceland in NCEP/NCAR), probably because of large inter-annual variability associated with 81 the northern hemispheric circumpolar vortex ${ }^{28}$.

82 To assess the vertical structure of the trends in the meridional temperature gradient, we 83 calculate a bulk north-south temperature difference across the North Atlantic using a two-box 84 method. On each pressure surface, annual-mean temperatures are averaged within a polar box $85\left(50-70^{\circ} \mathrm{N}, 10-80^{\circ} \mathrm{W}\right)$ and then subtracted from those averaged within a subtropical box (30$\left.8650^{\circ} \mathrm{N}, 10-80^{\circ} \mathrm{W}\right)$. This calculation yields a zonal-mean bulk meridional temperature 87 difference, and the trends in this quantity are shown in Figure 2. There is good agreement between the reanalysis datasets, with all three showing a significant weakening of the meridional temperature gradient in the lower atmosphere and a significant strengthening in 90 the upper atmosphere. There is a transition between these two influences at around $450 \mathrm{hPa}$.

91 There are some minor discrepancies, with NCEP/NCAR showing both a faster weakening of the meridional temperature gradient in the lower atmosphere and a faster strengthening aloft. 93 At $250 \mathrm{hPa}$, however, all three reanalysis datasets show a significant strengthening of the 94 temperature difference by nearly $0.2 \mathrm{~K} \mathrm{decade}^{-1}$, consistent with Figure 1.

95 To assess the impacts of the increasing meridional temperature gradient at $250 \mathrm{hPa}$ on the 96 atmospheric circulation, time series of the annual-mean vertical shear in zonal wind, averaged 97 over the region $30-70^{\circ} \mathrm{N}$ and $10-80^{\circ} \mathrm{W}$, are shown in Figure 3 (a). All three reanalysis 98 datasets are clearly in good agreement with respect to the inter-annual variability and the 
superimposed upward trend. The multi-reanalysis ensemble-mean vertical wind shear shows a significant $(p=0.03)$ increase of $15 \%\left(0.07 \mathrm{~m} \mathrm{~s}^{-1}(100 \mathrm{hPa})^{-1}\right.$ decade $\left.^{-1}\right)$ over the 39-year period. The individual increases range from $11 \%$ in JRA-55 $\left(0.06 \mathrm{~m} \mathrm{~s}^{-1}(100 \mathrm{hPa})^{-1}\right.$ decade $^{-1}$, $p=0.09)$ to $17 \%$ in ERA-Interim $\left(0.08 \mathrm{~m} \mathrm{~s}^{-1}(100 \mathrm{hPa})^{-1}\right.$ decade $\left.^{-1}, p=0.02\right)$ and $17 \%$ in NCEP/NCAR $\left(0.08 \mathrm{~m} \mathrm{~s}^{-1}(100 \mathrm{hPa})^{-1}\right.$ decade $\left.^{-1}, p=0.01\right)$. In contrast, as shown in Figure 3 (b), the annual-mean zonal wind speed averaged over the same region at $250 \mathrm{hPa}$ has not significantly changed in any of the three datasets $(p=0.72$ for the slope of the ensemblemean trend). It is notable that there is less spread between the three datasets for the shear than the speed, possibly because the speed is biased low in NCEP/NCAR because of the relatively coarse resolution compared to ERA-Interim and JRA-55, whereas this bias evidently disappears when vertical differences are taken to compute the shear.

The increased shear without increased speed shown for the upper atmosphere in Figure 3 indicates that the weaker meridional temperature gradient (and weaker vertical wind shear) in the lower troposphere is masking the stronger meridional temperature gradient (and stronger vertical wind shear) in the upper troposphere and lower stratosphere, through a large degree of cancellation in the vertically integrated thermal wind. We illustrate this effect by showing vertical profiles of trends in shear and speed throughout the depth of the troposphere in Extended Data Figure 1. The shear is strengthening within the jet core as well as throughout the broader region influenced by the jet stream (Extended Data Figure 2) and the trends are not attributable to a shift in the annual-mean latitude of the jet core (Extended Data

\section{Figure 3).}

To relate trends in the meridional temperature gradient to trends in the vertical shear, we invoke the time derivative of the thermal wind balance equation (1):

$$
-\frac{\partial}{\partial t} \frac{\partial u}{\partial p}=-\frac{R}{f p} \frac{\partial}{\partial t} \frac{\partial T}{\partial y}
$$


122 We calculate both sides of this equation independently at each grid-point, as a measure of the 123 extent to which the vertical wind shear changes are attributable to the local thermal wind 124 response to the meridional temperature gradient changes. The time derivatives are evaluated 125 as the linear trends over the period 1979-2017, calculated by applying ordinary least-squares 126 regression to annual-mean values of $\partial u / \partial p$ and $\partial T / \partial y$ at each grid-point on the $250 \mathrm{hPa}$ 127 pressure surface. Maps of the left side of equation (2) - the directly calculated vertical wind 128 shear trend, produced by differencing the wind fields at the two adjacent pressure levels - are 129 shown in Figure 4 (a, b, c). Maps of the right side of equation (2) - the expected vertical 130 wind shear trend, produced by using the temperature field and assuming thermal wind 131 balance - are shown in Figure $4 \mathbf{( d , e , ~ f ) . ~ T h e r e ~ i s ~ a ~ c l e a r ~ t r e n d ~ t o w a r d s ~ s t r o n g e r ~ v e r t i c a l ~}$ 132 shear at $250 \mathrm{hPa}$ over almost the entire North Atlantic domain in all three reanalysis datasets. 133 The trend is statistically significant in the core of the climatological jet stream and on the 134 poleward flank. We note the similarity in spatial patterns between these observed vertical 135 wind shear increases and future projections of increased clear-air turbulence ${ }^{18,19}$. The good 136 agreement between the left and right sides of equation (2), in terms of both the spatial 137 patterns (the pattern correlation coefficients are $r>0.70$ in all three datasets) and magnitudes, 138 confirms that the vertical wind shear trends are indeed largely attributable to the response of 139 the thermal wind to the meridional temperature gradient trends. The small discrepancies are 140 presumably attributable to the numerical finite differences used to estimate the derivatives, as 141 well as to weak ageostrophic and non-hydrostatic effects.

In summary, we have identified the first observationally based evidence of increased vertical wind shear in the North Atlantic upper-level jet stream over the satellite era (1979-2017). 144 The increase of $15 \%$ (with a range of $11-17 \%$ ) is statistically significant, is present in three 145 independently produced reanalysis datasets, and is attributable to the thermal wind response 146 to the strengthening upper-level meridional temperature gradient. The stronger shear is 
147 consistent with the intensification of clear-air turbulence expected from climate change ${ }^{18-20}$,

148 because clear-air turbulence is generated by strong vertical wind shear (which means small

149 Richardson number; we note that a 15\% shear increase implies roughly a 30\% Richardson

150 number decrease, because of their inverse square relationship). In contrast to the large

151 increase in vertical wind shear, we find that the zonal wind speed has not significantly

152 changed, consistent with previous studies ${ }^{11,12}$. The explanation for this effect is that, in the

153 vertically integrated thermal wind balance equation, the weaker meridional temperature

154 gradient and weaker vertical wind shear in the lower troposphere are mostly offsetting the

155 stronger meridional temperature gradient and stronger vertical wind shear aloft. Increased

156 vertical wind shear has important implications, not only for clear-air turbulence and its

157 impacts on aviation, but also for the turbulent mixing of atmospheric constituents across the

158 tropopause ${ }^{29}$, with potentially significant consequences for large-scale atmospheric 159 thermodynamics and dynamics ${ }^{30}$.

160 Our results indicate that climate change is having a larger impact on the North Atlantic jet 161 stream than previously thought. We conclude that the impacts of climate change and 162 variability on the upper-level jet stream are being partly obscured by the traditional focus on 163 speed rather than shear. We suggest that climate-modelling studies into the response of the jet 164 streams to climate change should therefore include consideration of the vertical shear as well 165 as the speed. We anticipate that inter-model differences in upper-level vertical wind shear 166 trends will have a clear interpretation in terms of different upper-level temperature trends. On 167 the other hand, inter-model differences in upper-level wind speed trends may be more 168 difficult to interpret, because of different balances in the competition between temperature 169 trends at upper and lower levels.

\section{References}


171 1. Wallace, J. M. \& Hobbs, P. V. Atmospheric Science: An Introductory Survey.

$172 \quad$ (Academic Press, 2006).

173 2. Held, I. M. Large-Scale Dynamics and Global Warming. Bull. Am. Meteorol. Soc. 74, $174 \quad 228-241(1993)$.

175 3. Thompson, D. W. J. \& Solomon, S. Recent stratospheric climate trends as evidenced 176 in radiosonde data: Global structure and tropospheric linkages. J. Clim. 18, 4785-4795

177 (2005)

4. Allen, R. J. \& Sherwood, S. C. Warming maximum in the tropical upper troposphere deduced from thermal winds. Nat. Geosci. 1, 399-403 (2008).

5. Mitchell, D. M., Thorne, P. W., Stott, P. A. \& Gray, L. J. Revisiting the controversial issue of tropical tropospheric temperature trends. Geophys. Res. Lett. 40, 2801-2806 (2013).

6. Sherwood, S. C. \& Nishant, N. Atmospheric changes through 2012 as shown by iteratively homogenized radiosonde temperature and wind data (IUKv2). Environ. Res. Lett. 10, 054007 (2015).

7. Lorenz, D. J. \& DeWeaver, E. T. Tropopause height and zonal wind response to global warming in the IPCC scenario integrations. J. Geophys. Res. Atmos. 112, 1-11 (2007).

8. Francis, J. A. \& Vavrus, S. J. Evidence linking Arctic amplification to extreme weather in mid-latitudes. Geophys. Res. Lett. 39, 1-6 (2012).

9. Haarsma, R. J., Selten, F. \& van Oldenborgh, G. J. Anthropogenic changes of the thermal and zonal flow structure over Western Europe and Eastern North Atlantic in CMIP3 and CMIP5 models. Clim. Dyn. 41, 2577-2588 (2013).

10. Francis, J. A. \& Vavrus, S. J. Evidence for a wavier jet stream in response to rapid 
Arctic warming. Environ. Res. Lett. 10, 014005 (2015).

11. Archer, C. L. \& Caldeira, K. Historical trends in the jet streams. Geophys. Res. Lett. 35, 1-6 (2008).

12. Pena-Ortiz, C., Gallego, D., Ribera, P., Ordonez, P. \& Del Carmen Alvarez-Castro, M. Observed trends in the global jet stream characteristics during the second half of the 20th century. J. Geophys. Res. Atmos. 118, 2702-2713 (2013).

13. Manney, G. L. \& Hegglin, M. I. Seasonal and Regional Variations of Long-Term Changes in Upper-Tropospheric Jets from Reanalyses. J. Clim. 31, 423-448 (2018).

14. Francis, J. A. Why are Arctic linkages to extreme weather still up in the air? Bull. Am. Meteorol. Soc. 98, 2551-2558 (2017).

15. Kalnay, E. et al. The NCEP/NCAR 40-year reanalysis project. Bull. Am. Meteorol. Soc. 77, 437-471 (1996).

16. Dee, D. P. et al. The ERA-Interim reanalysis: Configuration and performance of the data assimilation system. Q. J. R. Meteorol. Soc. 137, 553-597 (2011).

17. Kobayashi, S. et al. The JRA-55 Reanalysis: General Specifications and Basic Characteristics. J. Meteorol. Soc. Japan. Ser. II 93, 5-48 (2015).

18. Williams, P. D. \& Joshi, M. M. Intensification of winter transatlantic aviation turbulence in response to climate change. Nat. Clim. Chang. 3, 644-648 (2013).

19. Williams, P. D. Increased light, moderate, and severe clear-air turbulence in response to climate change. Adv. Atmos. Sci. 34, 576-586 (2017).

20. Storer, L. N., Williams, P. D. \& Joshi, M. M. Global Response of Clear-Air Turbulence to Climate Change. Geophys. Res. Lett. 44, 9976-9984 (2017). 
21. Lee, S. \& Kim, H. The Dynamical Relationship between Subtropical and Eddy-Driven Jets. J. Atmos. Sci. 60, 1490-1503 (2003).

22. Hannachi, A., Woollings, T. \& Fraedrich, K. The North Atlantic jet stream: A look at preferred positions, paths and transitions. Q. J. R. Meteorol. Soc. 138, 862-877 (2012).

23. Williams, P. D. Transatlantic flight times and climate change. Environ. Res. Lett. 11, 024008 (2016).

24. Vallis, G. K., Zurita-Gotor, P., Cairns, C. \& Kidston, J. Response of the large-scale structure of the atmosphere to global warming. Q. J. R. Meteorol. Soc. 141, 1479-1501 (2015).

25. Woollings, T. \& Blackburn, M. The North Atlantic jet stream under climate change and its relation to the NAO and EA patterns. J. Clim. 25, 886-902 (2012).

26. Stuecker, M. F., Bitz, C. M., Armour, K. C., Proistosescu, C. \& Kang, S. M. Polar amplification dominated by local forcing and feedbacks. Nat. Clim. Chang. 8, 10761081 (2018).

27. Fujiwara, M. et al. Introduction to the SPARC Reanalysis Intercomparison Project ( SRIP ) and overview of the reanalysis systems. Atmos. Chem. Phys. 17, 1417-1452 (2017).

28. Waugh, D. W., Sobel, A. H. \& Polvani, L. M. What is the polar vortex and how does it influence weather? Bull. Am. Meteorol. Soc. 98, 37-44 (2017).

29. Shapiro, M. A. Turbulent Mixing within Tropopause Folds as a Mechanism for the Exchange of Chemical Constituents between the Stratosphere and Troposphere. $J$. Atmos. Sci. 37, 994-1004 (1980).

30. Maycock, A. C., Joshi, M. M., Shine, K. P. \& Scaife, A. A. The circulation response to 


\section{Acknowledgements}

241 S.H.L. acknowledges support through a Ph.D. studentship from the Natural Environment 242 Research Council SCENARIO Doctoral Training Partnership (reference NE/L002566/1).

\section{Author contributions}

244 S.H.L. and P.D.W. jointly conceived the study. S.H.L. performed the data analysis and 245 produced the figures with input from P.D.W and T.H.A.F. All authors contributed to writing 246 the manuscript. The authors discussed the results with each other at all stages.

\section{Author information}

248 The authors declare no competing financial interests. Correspondence and requests for 249 materials should be addressed to P.D.W. (p.d.williams@reading.ac.uk).

250 Figure 1: Annual-mean temperature trends in the North Atlantic at $250 \mathrm{hPa}$ over the period 1979-2017. Linear trends are calculated using ordinary least-squares regression from the (a) ERA-Interim, (b) NCEP/NCAR, and (c) JRA-55 reanalysis datasets. Significant $253(p<0.05 ; n=39)$ trends are indicated by stippling.

Figure 2: Vertical profiles of trends in the annual-mean north-south temperature difference across the North Atlantic over the period 1979-2017. Linear trends are calculated from the (a) ERA-Interim, (b) NCEP/NCAR, and (c) JRA-55 reanalysis datasets. Red and blue shading represents positive and negative trends, respectively. Error bars represent the 95\% confidence intervals in the slope of the ordinary least-squares regression $259 \quad(n=39)$.

Figure 3: Time series of annual-mean wind characteristics in the North Atlantic at 261 250 hPa over the period 1979-2017. Panel (a) shows the vertical shear in the zonal wind, 
and panel (b) shows the zonal wind speed. Data are presented from the ERA-Interim, 263 NCEP/NCAR, and JRA-55 reanalysis datasets. Also shown are the mean of the three 264 reanalysis datasets and the linear trend in the mean.

265 Figure 4: Annual-mean trends in vertical shear in zonal wind in the North Atlantic at 266250 hPa over the period 1979-2017. Panels (a), (b), and (c) show the actual vertical wind 267 shear trends calculated from the wind field, whereas panels (d), (e), and (f) show the expected 268 vertical wind shear trends calculated from the temperature field using thermal wind balance. 269 Linear trends are calculated using ordinary least-squares regression from the (a, d) ERA270 Interim, (b, e) NCEP/NCAR, and (c, f) JRA-55 reanalysis datasets. Significant $(p<0.05$; $271 n=39)$ trends are indicated by stippling. To indicate the climatological jet stream position, 272 the 1979-2017 annual-mean zonal wind at $250 \mathrm{hPa}$ in each reanalysis dataset is also shown 273 (black contours every $5 \mathrm{~m} \mathrm{~s}^{-1}$ ).

\section{Methods}

275 The North Atlantic region was chosen partly because it is the world's busiest oceanic flight corridor. Due to the zonally extended nature of the polar jet stream in this region, transatlantic flights are typically affected by the strength and position of the jet stream throughout their entire flight paths. The effects of the jet stream on aircraft include headwinds, tailwinds, and clear-air turbulence. A further reason for choosing the North

280 Atlantic is that - unlike the North Pacific - it exhibits separate polar and subtropical jet 281 streams, allowing an analysis of the polar jet stream exclusively.

282 We used pressure-level zonal wind and temperature data from the ERA-Interim, 283 NCEP/NCAR, and JRA-55 reanalysis datasets at six-hourly analysis intervals from 1 January 2841979 to 31 December 2017 inclusive, giving 39 full years of data. All datasets were used on a 285 standard latitude-longitude grid $\left(0.75^{\circ}\right.$ for ERA-Interim, $2.5^{\circ}$ for NCEP/NCAR, and $1.25^{\circ}$ 
286 for JRA-55). Trends were calculated using ordinary least-squares regression, and statistical 287 significance was assessed at the 95\% confidence level $(p<0.05)$ according to a two-tailed $t$ 288 test. The effect of temporal autocorrelation on statistical significance was tested in the 289 computed annual-mean data and found to be negligible. Percentage changes were calculated 290 using the values of the fitted linear trend lines in 1979 and 2017.

291 To calculate the two-box zonal-mean bulk meridional temperature difference, we first 292 averaged the annual-mean temperature in a subtropical box $\left(30-50^{\circ} \mathrm{N}, 10-80^{\circ} \mathrm{W}\right)$ and a polar 293 box $\left(50-70^{\circ} \mathrm{N}, 10-80^{\circ} \mathrm{W}\right)$, with a cosine(latitude) weighting factor to account for the 294 convergence of grid points at high latitudes. The latitudinal bounds of these boxes were 295 chosen to be approximately either side of the climatological annual-mean jet stream latitude 296 in the North Atlantic. We then found the meridional temperature difference across the North 297 Atlantic by subtracting the subtropical box temperature from the polar box temperature.

298 The jet stream was analysed in the North Atlantic region $\left(10-80^{\circ} \mathrm{W}, 30-70^{\circ} \mathrm{N}\right)$. The annual299 mean regional-mean $250 \mathrm{hPa}$ vertical shear in zonal wind was calculated by taking a centred 300 vertical finite difference using the annual-mean zonal winds at 300 and $200 \mathrm{hPa}$ :

$$
-\left.\frac{\partial u}{\partial p}\right|_{250 \mathrm{hPa}} \approx \frac{u(200 \mathrm{hPa})-u(300 \mathrm{hPa})}{100 \mathrm{hPa}}
$$

301 We also calculated trends in the annual-mean regional-mean (area-weighted) zonal wind 302 speed at $250 \mathrm{hPa}$ over the North Atlantic region. Vertical profiles of vertical shear trends 303 were calculated by taking centred finite differences at $50 \mathrm{hPa}$ intervals for ERA-Interim and 304 JRA-55, and from neighbouring pressure levels in NCEP/NCAR (due to the spacing of 305 available pressure-level data). 
306 The annual-mean regional-maximum vertical shear was calculated by a similar centred307 difference method: we first subtracted the $300 \mathrm{hPa}$ zonal wind from the $200 \mathrm{hPa}$ zonal wind 308 and then found the maximum value within the North Atlantic region at each six-hourly 309 interval, before averaging the maximum values annually. For the annual-mean regional310 maximum zonal wind speed, we found the maximum $250 \mathrm{hPa}$ zonal wind speed within the 311 North Atlantic region at each six-hourly interval, before averaging annually. In both cases, 312 the latitude at which the maximum occurred was stored.

313 When the calculations in Figure 3 are repeated using the annual-mean regional-maximum 314 vertical shear, instead of the annual-mean regional-mean vertical shear, a significant 315 ensemble-mean increase of $11 \%(p<0.01)$ in the shear is found. The individual increases are $31610 \%$ in ERA-Interim $(p<0.01), 18 \%$ in NCEP/NCAR $(p<0.01)$, and $7 \%$ in JRA-55 $317(p<0.01)$ (Extended Data Figure 2). These results confirm that the shear is strengthening trends are not attributable to a shift in the annual-mean latitude of the jet core, which shows no significant trend over the period (Extended Data Figure 3).

We used the time derivative of the thermal wind balance equation to relate linear trends in the meridional temperature gradient to linear trends in the vertical wind shear. At $250 \mathrm{hPa}$, we calculated trends in the annual-mean values of $\partial u / \partial p$ (using the centred finite difference method outlined above) and $\partial T / \partial y$. The agreement between the two was assessed through Pearson’s correlation coefficient using an area-weighted pattern correlation.

According to thermal wind balance, the trend in the zonal wind speed in the upper troposphere and lower stratosphere is given by the vertical integral of equation (2). This vertical integral is performed throughout the depth of the free troposphere, starting from the top of the planetary boundary layer. Temperature gradients in the lower troposphere are 
included in the integral, and therefore Arctic amplification at low levels is able to influence the wind speed at upper levels. For example, written in equation form, we have:

$$
\frac{\partial u(250 \mathrm{hPa})}{\partial t}=\int_{p_{0}}^{450 \mathrm{hPa}} \frac{R}{f p} \frac{\partial}{\partial t}\left(\frac{\partial T}{\partial y}\right) d p+\int_{450 \mathrm{hPa}}^{250 \mathrm{hPa}} \frac{R}{f p} \frac{\partial}{\partial t}\left(\frac{\partial T}{\partial y}\right) d p \approx 0
$$

where $p_{0}$ is the pressure at the top of the planetary boundary layer. Here, the free troposphere has been divided into two layers at $450 \mathrm{hPa}$, by reference to Figure 2. The lower boundary term $\partial u\left(p_{0}\right) / \partial t$ arising from the vertical integration has been neglected in equation (4), because the trend in zonal wind speed in the lower troposphere is not significantly different from zero in any of the reanalysis datasets, as shown in Extended Data Figure 1 (d, e, f). Our study shows that, on the right-hand side of equation (4), the first integral (which includes the weakening low-level temperature gradient from Arctic amplification) and the second integral (which includes the strengthening upper-level temperature gradient) are essentially equal and opposite when averaged over the North Atlantic region, thus largely cancelling out and leaving no significant trend in the upper-level speed.

\section{Data availability statement}

The NCEP/NCAR reanalysis data may be obtained from the National Oceanic and Atmospheric Administration (NOAA) Oceanic and Atmospheric Research (OAR) Earth System Research Laboratory (ESRL) Physical Sciences Division (PSD), Boulder, Colorado, USA (https://www.esrl.noaa.gov/psd/). The ERA-Interim and JRA-55 reanalysis data may be obtained from the Research Data Archive at the National Center for Atmospheric Research (NCAR), Computational and Information Systems Laboratory, Boulder, Colorado, USA (https://doi.org/10.5065/D6CR5RD9 and https://doi.org/10.5065/D6HH6H41, respectively).

\section{Code availability statement}


351 The analytical computer codes are publicly available at 352 http://doi.org/10.5281/zenodo.3238842.

353 Extended Data Figure 1: Vertical profiles of annual-mean trends in wind characteristics

354 in the North Atlantic over the period 1979-2017. Panels (a, b, c) show trends in the 355 vertical shear in the zonal wind, and panels (d, e, f) show trends in the zonal wind speed. 356 Linear trends are calculated from the (a, d) ERA-Interim, (b, e) NCEP/NCAR, and (c, f) JRA35755 reanalysis datasets. Red and blue shading represents positive and negative trends, 358 respectively. Error bars represent the 95\% confidence intervals in the slope of the ordinary 359 least-squares regression $(n=39)$.

360 Extended Data Figure 2: Annual-mean regional-maximum six-hourly vertical shear in 361 zonal wind in the North Atlantic at $250 \mathrm{hPa}$ over the period 1979-2017. Data are 362 presented from the ERA-Interim, NCEP/NCAR, and JRA-55 reanalysis datasets. Also shown 363 are the mean of the three reanalysis datasets and the linear trend in the mean.

364 Extended Data Figure 3: Annual-mean latitude of the core of the polar jet stream in the 365 North Atlantic at 250 hPa over the period 1979-2017. Panel (a) shows the annual-mean 366 latitude of the regional-maximum six-hourly vertical shear in zonal wind, and panel (b) 367 shows the annual-mean latitude of the regional-maximum six-hourly zonal wind speed. Data 368 are presented from the ERA-Interim, NCEP/NCAR, and JRA-55 reanalysis datasets. Also 369 shown are the mean of the three reanalysis datasets and the linear trend in the mean, which 370 has a statistically insignificant slope of (a) -0.1 degrees decade $^{-1}(p=0.54)$ and (b) 3710.01 degrees decade ${ }^{-1}(p=0.76)$. 

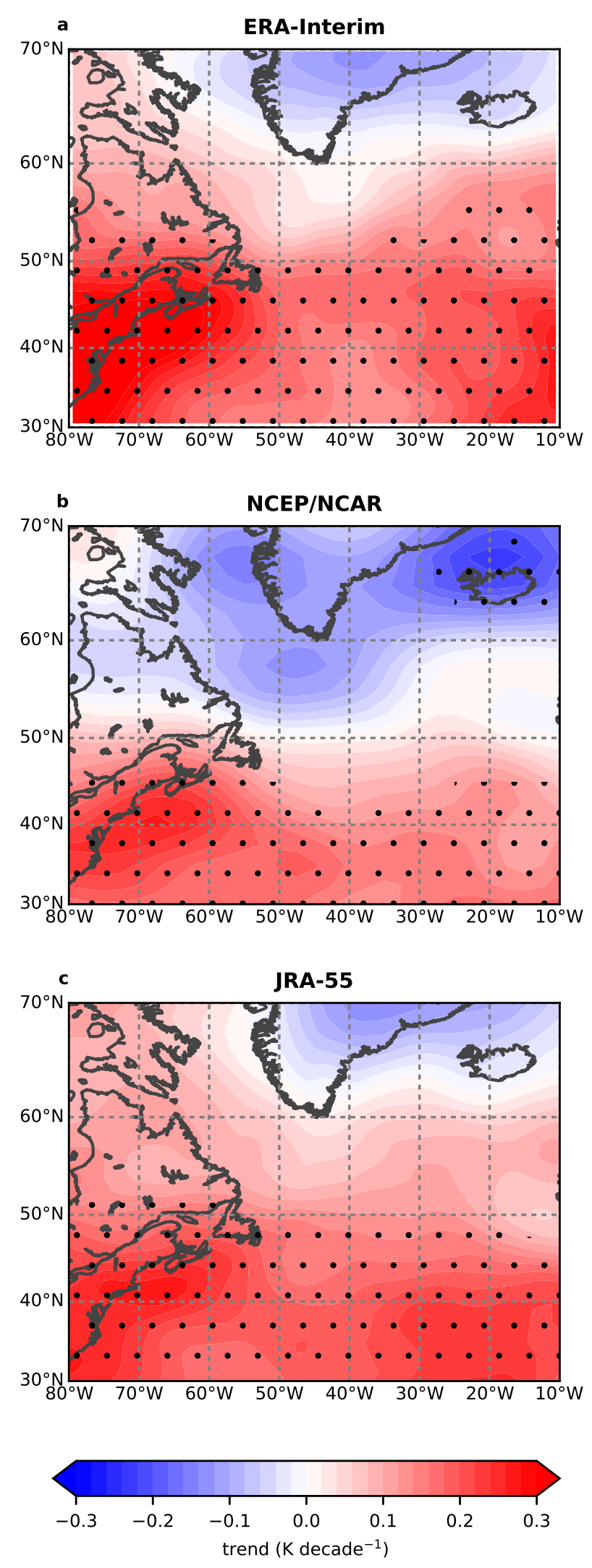

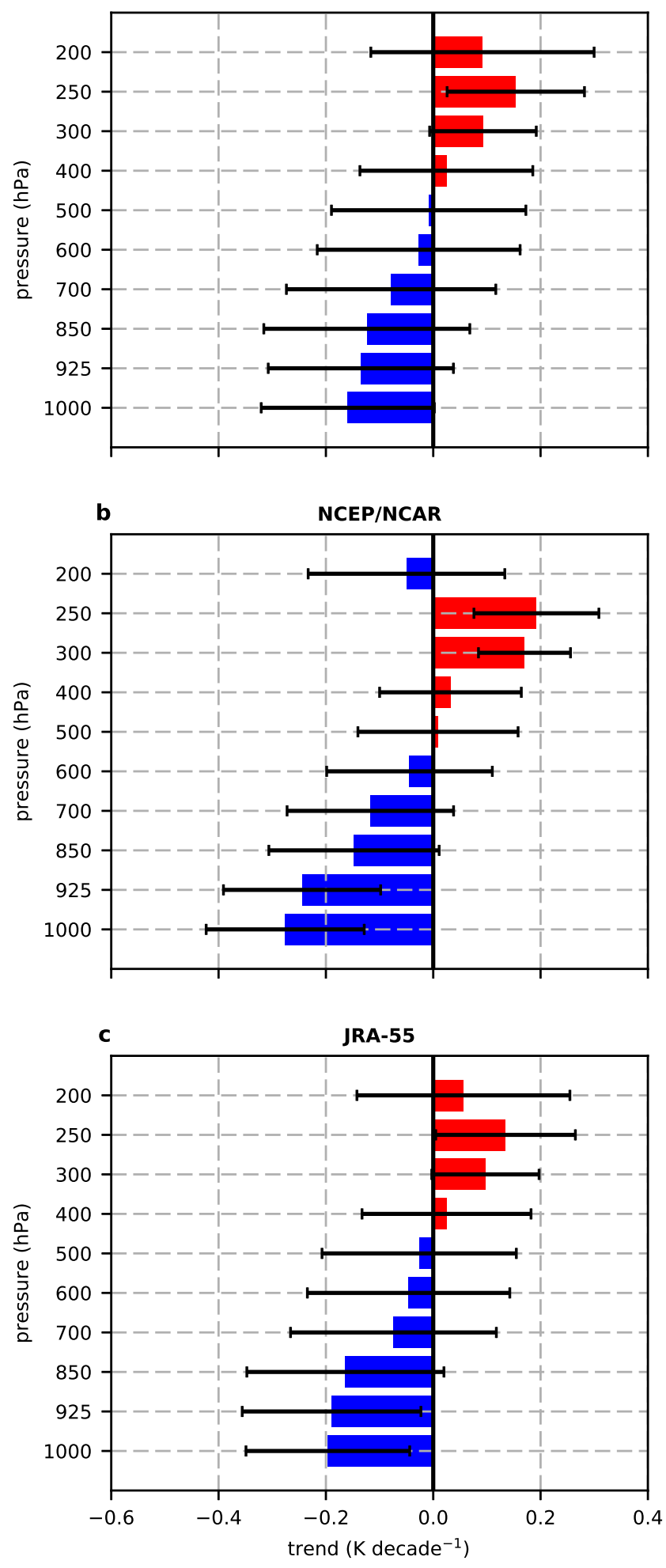

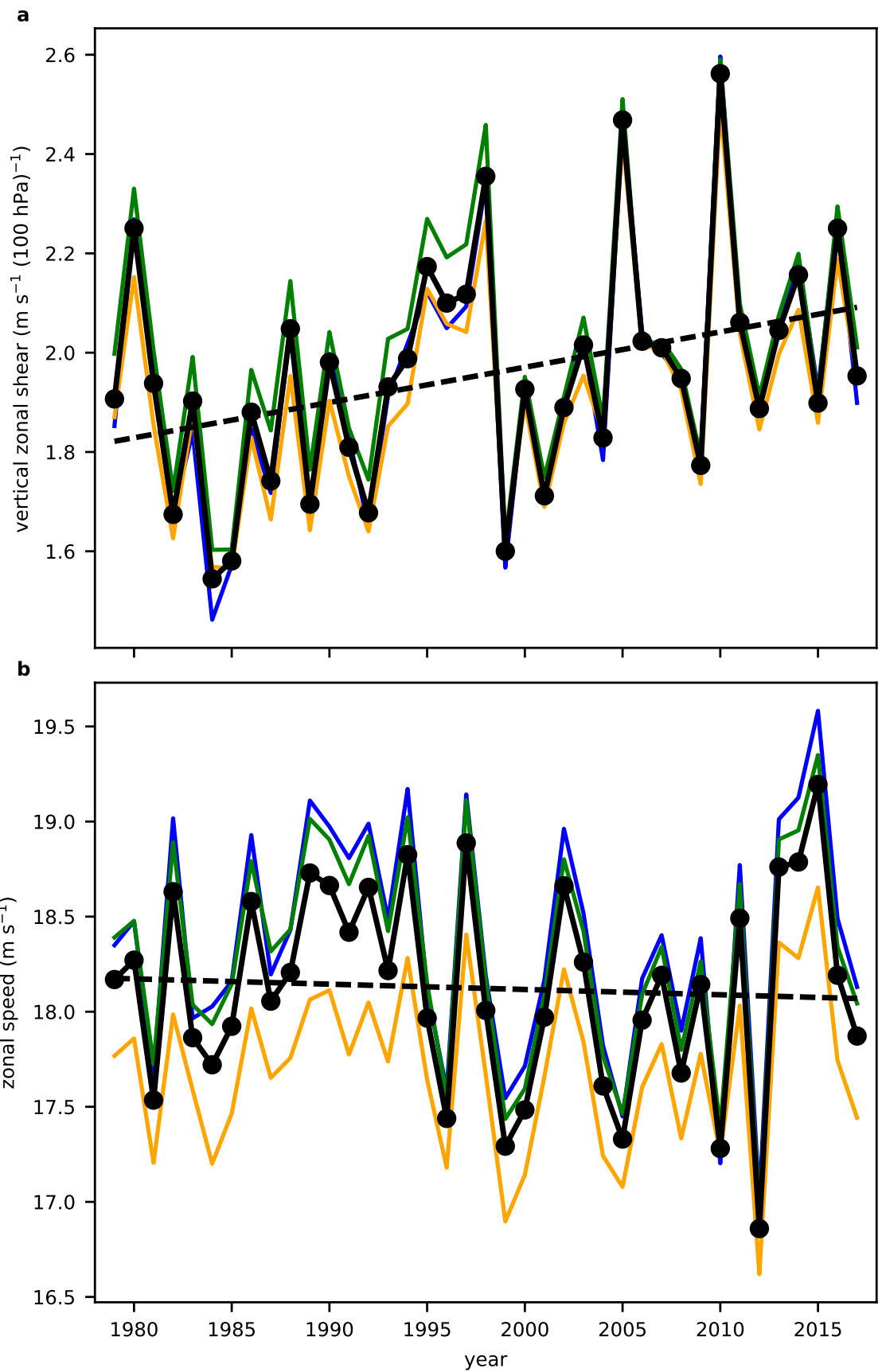
a

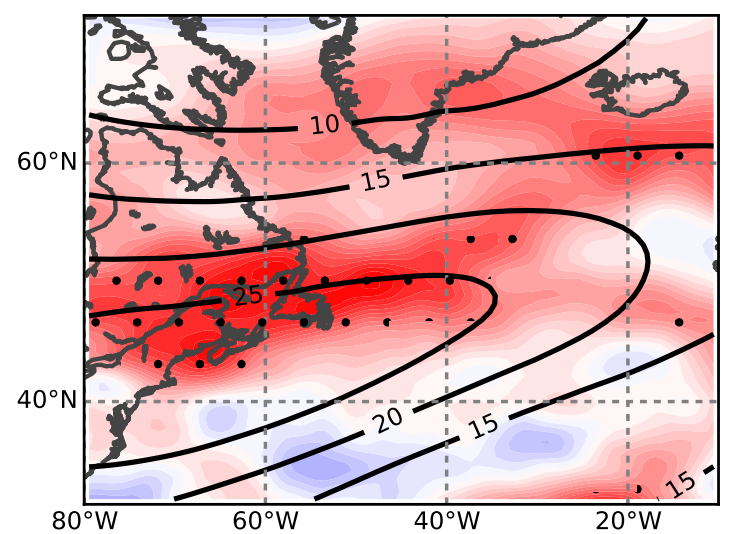

b

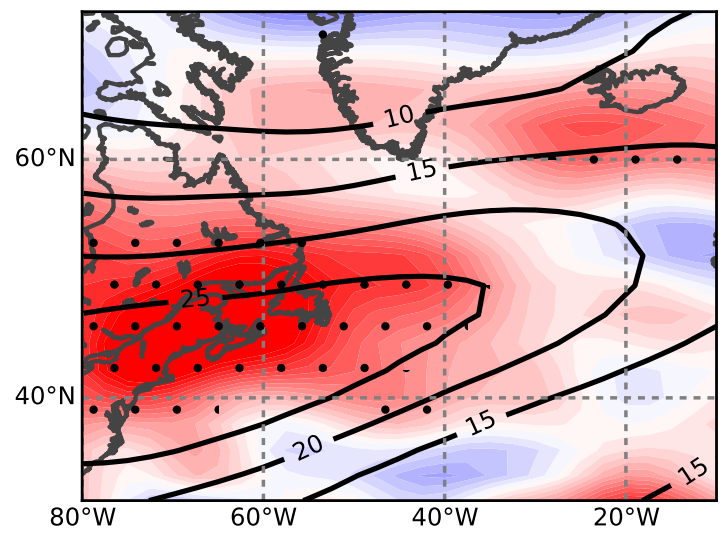

c

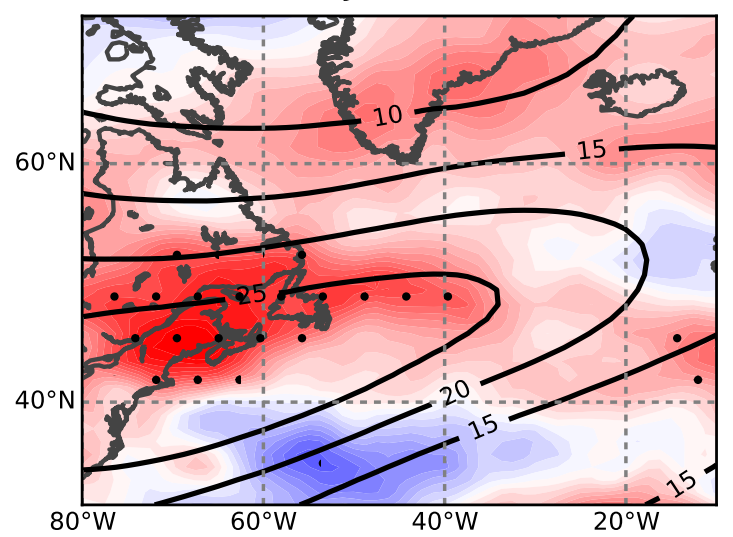

d

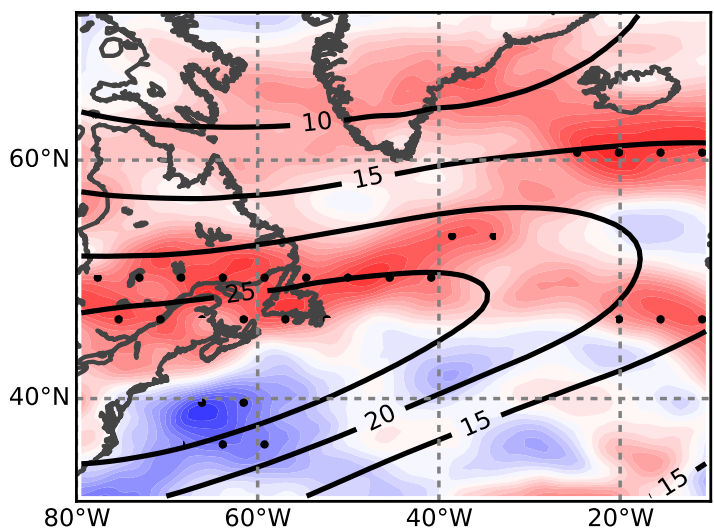

e
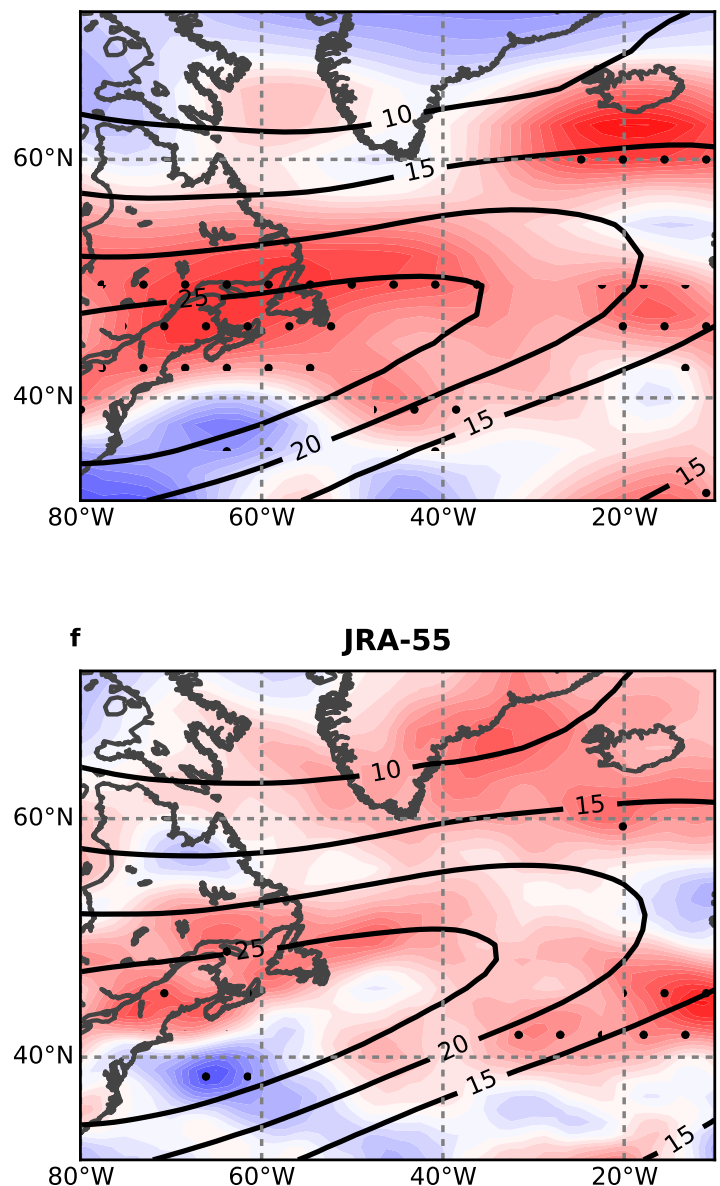

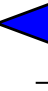

$-0.3$

$-0.2$

$-0.1$

0.0

0.1

0.2

0.3 